\title{
Pengaruh Terapi Oksigen Menggunakan Non-Rebreathing Mask Terhadap Tekanan Parsial CO2 Darah pada Pasien Cedera Kepala Sedang
}

\author{
Hendrizal $^{1}$, Syaiful Saanin ${ }^{1}$, Hafni Bachtiar ${ }^{2}$
}

\begin{abstract}
Abstrak
Tekanan parsial CO2sangat berpengaruh terhadap aliran darah otak (ADO) dan tekanan intra kanial. Latarbelakang penelitian ini adalah bahwa dalam teori tekanan gas campuran John Dalton dinyatakan bahwa jika salah satu tekanan gas dalam campuran gas bertambah maka tekanan parsial gas lain akan menurun. Penelitian ini bertujuan untuk mengetahui apakah peningkatan konsentrasi oksigen dalam Non-Rebreathing Mask (NRM) akan menurunkan tekanan parsial $\mathrm{CO} 2$, sehingga dapat digunakan untuk menurunkan $\mathrm{PaCO} 2$ sambil memperthankan $\mathrm{PaO} 2$ yang tinggi untuk menurunkan TIK (Tekanan Intra Kranial) pada pasien cedera kepala. Metode: Penelitian ini merupakan penelitian Clinical Trial dengan rancangan penelitian one shoot pretest and postest pada pasien cedera kepala sedang dengan GCS 9-13 yang dilakukan terapi konservatif di RS Dr. M. Djamil Padang. Pada pasien dinilai tekanan parsial CO2 darah sebelum dan setelah 6 jam terapi oksigen menggunakan NRM. Jumlah sampel sebanyak 16 pasien yang memenuhi kriteria inklusi. Hasil: Dari hasil penelitian didapatkan perbedaan bermakna tekanan parsial $\mathrm{CO} 2$ darah sebelum dan setelah terapi oksigen menggunakan NRM $(p<0,05)$. Terjadi penurunan tekanan parsial CO2 darah setelah terapi oksigen mengunakan NRM dari39,00 $\pm 3,7$ menjadi 432,06 $\pm 6,35$. Pembahasan: Terapi oksigen menggunakan NRM dapat menurunkan tekanan parsial $\mathrm{CO} 2$ darah sehingga dapat digunakan untuk menurunkan tekanan intrakranial pada pasien cedera kepala sedang.
\end{abstract}

Kata kunci: Terapi Oksigen, Non-Rebreathing Mask, Tekanan Parsial CO2 Darah

\begin{abstract}
The partial pressure of $\mathrm{CO} 2$ is very influential on cerebral blood flow (CBF) and intra kanial pressure. The background of this research is that the pressure of the gas mixture in the theory of John Dalton stated that if one of the gas pressure in the gas mixture increases, the partial pressure of other gases will decline. This study aimed to determine whether the increase in oxygen concentration in the non-rebreathing mask (NRM) will decrease the partial pressure of $\mathrm{CO} 2$, so that it can be used to decrease $\mathrm{PaCO} 2$ while $\mathrm{PaO} 2$ still higher to protect brain from higher of ICT (intra-cranial pressure) state in patients with head injuries. Method: This research is a Clinical Trial with one shoot pretest and posttest design in patients with moderate head injury with GCS 9-13 conducted conservative treatment at the hospital Dr. M. Djamil Padang. In patients assessed blood CO2 partial pressure before and after 6 hours of oxygen therapy using the NRM. Total sample of 16 patients who met the incluton criteria. Result: The result showed significant differences in blood CO2 partial pressure before and after oxygen therapy using the NRM $(P<0.05)$. There was a decrease of bloodCO2partial pressureafter oxygen therapy using NRM from $32.06 \pm 6.35$ to $39.00 \pm 3.74$. Discussion: Oxygen therapy using NRM can decrease blood $\mathrm{CO} 2$ partial pressure that can be used to reduce the intra-cranial pressure in patients with moderate head injury.
\end{abstract}

Keywords: Oxygen Therapy, Non-Rebreathing Mask, Blood CO2 Partial Pressure

Affiliasi penulis : 1. Bagian Bedah Fak Kedokteran Unand, 2 Bagian Ilmu Kesehatan Masyarakat Fakultas Kedokteran Unand,

Korespondensi : Hendrizal, email : hendrizalzubir@gmail.com, Telp/Hp : 08127657530

\section{PENDAHULUAN}

Insiden cedera kepala dari tahun ketahun makin meningkat seiring dengan meningkatnya mobilisasi penduduk. Di Amerika Serikat, sekitar 500.000 kasus pertahun pasien yang masuk ke rumah sakita dalah penderita cedera kepala dan 17.500 diantarnya meninggal pertahun. ${ }^{1}$ Di Indonesia sendiri belum ada data lengkap, dari data rekam medik di RSUPN Dr. Cipto Mangunkusumo Jakarta tahun 1998 tercatat penderita cedera kepala sebanyak 1091 orang dengan cedera kepala berat 137 orang. Di RSA "Jaury" Ujung Pandang pada tahun 1997, tercatat dari
6128 penderita yang dirawat, 322 diantaranya adalah penderita cedera kepala. ${ }^{1,2}$

Cedera kepala menempati peringkat tertinggi penderita yang dirawat di Bagian Bedah Saraf RS M. Djamil Padang. Data Bagian Bedah Saraf tahun2000 tercatat 534 penderita cedera kepala yang dirawat dengan angka kematian mencapai lebih $10 \%$ dan tahun 2011 sebanyak 502 orang. Tingginya angka kesakitan dan kematian akibat cedera kepala menjadikan tantangan bagi spesialis Bedah Saraf untuk menurunkannya. Untuktujuan tersebut diperlukan suatu penanganan yang komprehensif baik yang mencakup diagnosa, terapi dan prognosis., ${ }^{2,3}$

Pengelolaan cedera kepala yang baik harus dimulai dari tempat kejadian, selama transportasi, di instalasi gawat darurat, hingga dilakukannya terapi definitif. Pengelolaan yang benar dan tepat akan mempengaruhi outcome pasien. Tujuan utama 
pengelolaan cedera kepala adalah mengoptimalkan pemulihan dari cedera kepala primer dan mencegah cedera kepala sekunder yang disebabkan oleh iskemi kotak. Proteksi otak adalah serangkaian tindakan yang dilakukan untukmencegah atau mengurangi kerusakan

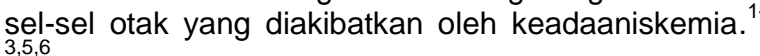

Pengenalan asam basa sangat penting untuk pengelolaan pasien bedah saraf, terutama pasien bedah saraf yang menjalani perawatan intensif. Sebagai contoh pasien cedera kepala sedang, pada pasien ini dapat terjadi asidosis jaringan otak yang dapat menyebabkan terjadinya edema serebral karena terhalangnya tranpor $\mathrm{Na}^{+}$dan $\mathrm{H}^{+}$serta $\mathrm{Cl}^{-}$dan $\mathrm{HCO}_{3}^{-}$. Faktor yang mempengaruhi regulasi asam basa jaringan otak adalah kadar $\mathrm{CO}_{2}$, sistem buffer, serta penambahan asam metabolit oleh metabolisme tubuh. $^{7-12}$

Dari berbagai kepustakaan, didapatkan bahwa angka kejadian dari perubahan $\mathrm{PaO}_{2}$ dan $\mathrm{PaCO}_{2}$ pada cedera kepala berat sangatlah bervariasi, nilainya berkisar antara 30 hingga $84 \%$, angka kematian yang diakibatkan oleh perubahan tekanan gas tersebut adalah berkisar antara $16-30 \%$, dan $10-$ $20 \%$ diantaranya melalui mekanisme vasodilatasi dan peningkatan laju aliran darah ke otak. ${ }^{2}$ Perubahan $\mathrm{PaCO}_{2}$ pada penderita cedera kranioserebral berat sangatlah bervariasi. Namun semua kepustakaan sepakat, bahwa $\mathrm{PaCO}_{2}$ arteri harus dijaga dalam ambang batas normal. Apabila $\mathrm{PaCO}_{2}$ meningkat, akan terjadi vasodilatasi pembuluh darah otak yang menyebabkan peningkatan laju aliran darah ke otak, dan akhirnya akan terjadi peningkatkan tekanan intrakranial. Peningkatan tekanan intrakranial ini dengan berbagai implikasinya merupakan faktor yang harus dicegah dikarenakan akan memperburuk hasil keluaran yang ada. Sementara itu, apabila kadar $\mathrm{PaCO}_{2}$ arteri turun terlalu rendah, melalui mekanisme vasokonstriksi akan menyebabkan spasme pada pembuluh darah otak serta mengancam terjadinya iskemik. ${ }^{8}$ Weiner mengemukakan bahwa penurunan 1 $\mathrm{mmHg} \mathrm{PaCO}_{2}$ akan menurunkan laju aliran darah ke otak sebesar $2 \%$. Beberapa peneliti memberi batasan angka kadar $\mathrm{PaCO}_{2}$ normal antara $35-45 \mathrm{mmHg}$ (beberapa penulis menyebut angka $30 \mathrm{mmHg}$ sebagai batas minimal bagi laju aliran darah ke otak yang adekuad) oleh $\mathrm{PaCO}_{2}$ yang melebihi $45 \mathrm{mmHg}$ sudah dapat meningkatkan tekanan intrakranial, karena terjadi peningkatan aliran darah ke otak sedangkan bila $\mathrm{PaCO}_{2}$ menurun hingga $26 \mathrm{mmHg}$ dan terus menurun hingga di bawah $25 \mathrm{mmHg}$, maka CBF(cerebralblood flow) akan turun di bawah angka kurang dari $17 \mathrm{mmHg} / 100$ gr/menit (Currie memberikan angka suatu penurunan CBF di bawah 20 $\mathrm{cc} / 100 \mathrm{gr} / \mathrm{menit})$. $_{1,8-11}$

Dari kepustakaan, didapatkan keterangan bahwa perubahan $\mathrm{PaO}_{2}$ arteri, tidak memiliki akibat sebesar perubahan $\mathrm{PaCO}_{2}$, namun mereka pun sepakat untuk menjaga $\mathrm{PaO}_{2}$ tetap dalam ambang batas normal bahkan cenderung tinggi. Apabila $\mathrm{PaO}_{2}$ berada dalam kadar yang terlalu rendah, maka akan menimbulkan hipoksia yang dapat menyebabkan vasodilitasi pembuluh darah otak yang akan diikuti oleh peningkatan laju aliran darah ke otak, dan mengakibatkan terjadinya peningkatan tekanan intracranial. Apabila kadar $\mathrm{PaO}_{2}$ terlalu tinggi, akan terjadi vasokonstriksi pembuluh darah. Winer menyebutkan bahwa perubahan kadar $\mathrm{PaO}_{2}$ sebanyak $15 \%$ persen, hanya akan mengubah sedikit aliran darah ke otak. ${ }^{1,9-11}$

Pada pasien cedera kepala penting menjaga kadar $\mathrm{PaO}_{2}$ Dalam batas normal. $\mathrm{Di}$ beberapa kepustakaan disebutkan bahwa sebaiknya kita menjaga $\mathrm{PaO}_{2}$ minimal $100 \mathrm{mmHg}$, bahkan ada penulis yang memberikan nilai yang lebih tinggi, yaitu berkisar antara 140-160 mmHg. Pemberian oksigen bisa menggunakan nasal canul, oksigen mask atau dengan oksigen hiperbarik chamber.,

Salah satu cara tata laksana untuk mengendalikan peningkatan tekanan intrakranial adalah dilakukan suatu tindakan penurunan $\mathrm{PaCO}_{2}$, pada fase akut terjadinya trauma. Penurunan dilakukan hingga mencapai kadar $\mathrm{PaCO}_{2}$ sekitar 20-30 $\mathrm{mmHg}$, yang dikenal sebagai tindakan hiperventilasi. Penurunan $\mathrm{PaCO}_{2}$ ini akan menyebabkan vasokonstriksi pembuluh darah otak dan kondisi ini secara langsung akan menyebabkan penurunan laju aliran darah ke otak; dengan akibat (secara tidak langsung) akan menurunkan tekanan intrakranial. ${ }^{10,12}$

Latar belakang penelitian ini adalah bahwa dalam teori tekanan gas campuran Dalton mengatakan bahwa jika salah satu tekanan gas dalam campuran gas bertambah maka tekanan parsial gas lain akan menurun, sehingga penulis ingin mengetahui apakah peningkatan konsentrasi oksigen dalam NonRebreathing mask akan menurunkan tekanan parsial $\mathrm{CO} 2$, sehingga dapat digunakan untuk menurunkan $\mathrm{PaCO}_{2}$ sambil memperthankan $\mathrm{PaO}$ 2yang tinggi untuk menurunkan TIK (Tekanan Intra Kranial) pada pasien cedera kepala.

Pada pasien cedera kepala perlu menjaga kestabilan $\mathrm{PaO} 2$ dengan terapi oksigen dan mencegah terjadinya peningkatan $\mathrm{PaCO}$, diantaranya dengan menggunakan NRM (Non rebreathing Mask). Apakah terapi oksigen dengan NRM berpengaruh terhadap perubahan $\mathrm{PaCO} 2$.

\section{METODE}

Peneltian ini merupakan penelitian Clinical Trial dengan rancangan penelitian one shoot pretest and postest. Penelitian dilakakukan di RS Dr. M. Djamil Padang, bertempat di IGD danruang HCU (High Care Unit) bedah. Populasi penelitian adalah semua pasien cedera kepal amurni GCS 9-13 yang datang berobat ke IGD RS Dr. M. Djamil Padang.

Sampel penelitian adalah pasien cedera kepala Murni GCS 9-13. Pengambilan sampel menggunakan non-probability sampling dengan teknik consecutive sampling karena populasi penelitian tidak bisa dihitung (infinite). Pada penelitian eksperimental jumlah sampel adalah 16 pasien.

\section{HASIL}

Telah dilakukan penelitian Clinical Trial terhadap 16 pasien cedera kepala sedang yang masuk ke IGD RS Dr. M. Djamil Padang dari tanggal 15 November 2012 sampai 2 Januari 2013 yang memenuhi kriteria inklusi dan ekslusi. Berdasarkan karakteristik responden rata-rata umur pasien adalah 18 tahun dengan standar deviasi 14,81 . 
Tabel 1. Sebaran frekuensi pH darah sebelum terapi oksigen dengan NRM

\begin{tabular}{lcc}
\hline \multicolumn{1}{c}{$\mathbf{p H}$} & $\mathbf{f}$ & $\%$ \\
\hline Tinggi $(>7,45)$ & 0 & 0 \\
Normal $(7,35-7,45)$ & 16 & 100 \\
Rendah $(<7,35)$ & 0 & 0 \\
Total & 16 & 100 \\
\hline
\end{tabular}

Dari Tabel 1 terlihat semua $\mathrm{pH}$ darah sebelum terapi oksigen menggunakan NRM dalam batas normal.

Tabel 2. Sebaran frekuensi pH darah setelah terapi oksigen dengan NRM

\begin{tabular}{lcc}
\hline \multicolumn{1}{c}{$\mathbf{p H}$} & $\mathbf{f}$ & $\%$ \\
\hline Tinggi $(>7,45)$ & 2 & 12,5 \\
Normal $(7,35-$ & 12 & 75 \\
$7,45)$ & 2 & 12,5 \\
Rendah $(<7,35)$ & 16 & 100 \\
\hline Total & \\
\hline
\end{tabular}

Dari Tabel 2 di atas dapat dilihat bahwa $\mathrm{pH}$ darah setelah penggunaan terapi oksigen dengan NRM sebagian besar normal dengan persentase $75 \%$.

Tabel 3. Sebaran frekuensi $\mathrm{pCO}_{2}$ darah sebelum terapi Oksigen dengan NRM

\begin{tabular}{lcc}
\hline $\begin{array}{c}\text { pCO2 Darah } \\
(\mathbf{m m H g})\end{array}$ & $\mathbf{f}$ & $\%$ \\
\hline Tinggi $(>45)$ & 0 & 0 \\
Normal $(35-45)$ & 16 & 100 \\
Rendah $(<35)$ & 0 & 0 \\
\hline Total & 16 & 100 \\
\hline
\end{tabular}

Pada Tabel 3. tampak $\mathrm{pCO}_{2}$ darah sebelum penggunaan terapi oksigen menggunakan NRM semuanya dalam batas normal (100\%).

Tabel 4. Sebaran frekuensi $\mathrm{pCO}_{2}$ darah setelah terapi Oksigen dengan NRM

\begin{tabular}{lcc}
\hline $\begin{array}{l}\text { pCO2 Darah } \\
(\mathbf{m m H g})\end{array}$ & $\mathbf{f}$ & $\%$ \\
\hline Tinggi $(>45)$ & 1 & 6,25 \\
Normal $(35-45)$ & 2 & 12,5 \\
Rendah $(<35)$ & 13 & 81,25 \\
\hline Total & 16 & 100 \\
\hline
\end{tabular}

Dari Tabel 4. Terlihat bahwa setelah penggunaan terapi oksigen menggunakan NRM sebagian besar pCO2 menjadi rendah dengan persentase $81,25 \%$.

Tabel 5. Perubahan $\mathrm{pCO}_{2}$ sebelum dan setelah terapi Oksigen menggunakan NRM

\begin{tabular}{lcc}
\hline & Rata-rata & $\begin{array}{c}\text { Standard } \\
\text { deviasi }\end{array}$ \\
\hline $\mathrm{pCO}_{2}$ sebelum & 39,00 & 3,74 \\
\hline $\mathrm{pCO}_{2}$ setelah & 32,06 & 6,35 \\
\hline
\end{tabular}

Bahwa berdasarkan Tabel 5 . terdapat penurunan $\mathrm{pCO}_{2}$ darah setelah terapi oksigen menggunakan NRM dari $32,06 \pm 6,35$ menjadi 39,00 $\pm 3,74$.

Analisa statistik dengan Paired $t$ test didapatkan hubungan bermakna $\mathrm{pCO}_{2}$ darah sebelum dan sesudah terapi oksigen menggunakan NRM dengan nilai signifikan $(p<0,05)$.

\section{PEMBAHASAN}

Dari hasil penelitian terhadap 16 sampel pasien cedera kepala sedang dari bulan Desember 2012 sampai Januari 2013 yang masuk IGD RS. Dr. M. Djamil Padang didapatkan nilai rata-rata $\mathrm{pCO}_{2}$ sebelum dan sesudah terapi oksigen menggunakan non-rebreathing mask masing-masing 32,06 $\pm 6,35$ dan $39,00 \pm 3,74$. Nilai $\mathrm{pH}$ darah setelah pemberian terapi ini $75 \%$ berada pada nilai normal.

Dari hasil paired $t$ test didapat hubungan bermakna $\mathrm{pCO}_{2}$ sebelum dan setelah terapi oksigen menggunakan NRM dan terjadi penurunan rata-rata nilai $\mathrm{pCO}_{2}$ setelah pemberian terapi oksigen. Dari hasil ini uji ini disimpulkan Hipotesis penelitian dapat diterima. Hasil penelitian ini sesuai dengan teori tekanan gas campuran menurut "John Dalton", bahwa tingginya fraksi inspirasi $\mathrm{O}_{2}$ akan meningkatkan tekanan parsial gas tersebut yang dapat menurunkan tekanan parsial $\mathrm{CO}_{2}$ dalam NRM. Menurut "Guyton A". tekanan parsial oksigen dalam alveoli adalah 104 $\mathrm{mmHg}(13,6 \%)$ dari tekanan total gas campuran, sedangkan karbondioksida $27 \mathrm{mmHg}$. Terapi oksigen mengunakan NRM dapat meningkatkan fraksi inspirasi oksigen lebih dari $90 \%$ sehingga pengaruh penggunaan NRM ini juga akan menurunkan tekanan parsial gas dalam alveoli. Tingginya $\mathrm{pO}_{2}$ dalam alveoli juga menimbulkan efek Halden dimana tekanan parsial oksigen yang tinggi akan meningkatkan pelepasan ikatan $\mathrm{CO}_{2}$ dengan haemoglobin dalam darah. Akibat lanjut adalah kecepatan difusi gas dari darah ke alveoli meningkat akibat perbedaan tekanan parsial karbondioksida lebih besar.

Dari gambaran $\mathrm{pH}$ darah dapat dilihat bahwa $75 \%$ berada pada batas normal setelah dilakukan terapi oksigen dengan NRM, sesuai dengan "Guyton A" bahwa penurunan $\mathrm{pCO}_{2}$ akan menurunkan $\mathrm{pH}$ darah, tetapi tubuh mempunyai system buffer yang akan mengatur $\mathrm{pH}$ dalam batas normal.

\section{KESIMPULAN}

1. Nilai $\mathrm{pH}$ darah setelah terapi oksigen menggunakan Non-rebreathing mask sebagian besar dalam batas normal.

2. Nilai $\mathrm{pCO}_{2}$ darah setelah terapi oksigen menggunakan Non-rebreathing mask sebagan besar dibawah normal.

3. Terjadi penurunaan $\mathrm{pCO}_{2}$ darah pada terapi oksigen menggunakan Non-rebreathing mask.

\section{Saran}

Non-rebreathing mask Dapat digunakan untuk menurunkan $\mathrm{pCO}_{2}$ darah antara 25 sampai $35 \mathrm{mmHg}$ pada pasien cedera kepala sedang yang mengalami peningkatan tekanan intra kanial akibat cedera otak sekunder dengan melakukan pemantauan ketat analisa gas darah pada fase akut. Perlu monitoring analisa gas darah pada pasien cedera kepala yang menggunakan terapi oksigen menggunakan Nonrebreathing mask. 


\section{DAFTAR PUSTAKA}

1. Tisdal M, Tachtsidis I, Terence S,et. al: Increase in Cerebral Aerobic Metabolism bynormobaric Hyperoxia after traumatic brain injury. J. Neurosurg.109. 2008.

2. Arifin MZ. KorelasiAntara Kadar Oxygen Delivery dengan Length of Stay pada Pasien Cedera Kepala Sedang. Pustaka UNPAD. 2008.

3. Bullock MR, Povlishock JT (2007) Guidelines for the management of severe traumatic brain injury. J Neurotrauma 24(Suppl 1):S87-S90

4. Raj K Narayan, Suzanne K, Closed Head Injury in Principles ofNeurosurgery second edition, Elsevier Mossby, Edinburgh 2005.

5. Mark S. Greenberg; Handbook Of Neurosurgery Sixth Edition, ThiemeMedical Publisher, New York, 2006.

6. LiauL.M., M. Bergsneider, D.P. Becker, Pathology and Pathophysiologyof Head Injury, Youmans Neurological Surgery Fourth Edition VolumellI, E Book's Edition.

7. Sumantri U.F: Resiko Kematian pada Pasien Cedera Kranioserebral Berat Ditinjau dari Aspek $\mathrm{PaO}_{2}$ dan $\mathrm{PaCO}_{2}$. Tesis.Perpustakaan UI. 2005.

8. Clausen $T$, Khaldi A, Zauner A, et al. Cerebral acid-base homeostasis after severe traumatic brain injury. J Neurosurg 2005; 103:597-607 LINK

9. Kontos HA, Raper AJ, Patterson JL Jr. Analysis of Vasoactivityof Local pH, pCO2, and Bicarbonate on Pial Vessels. Stroke 1977;8:358-360.

10. Stocchetti N, et al. Hyperventilation in Head Injury. Chest Journal. 127. 2005.

11. Myburg J.A. et. Al.Cerebrovascular Carbon Dioxide Reactivity in Sheep:Effect of Propofol or IsofluraneAnaesthesia. J AnaesthIntensive. 30. Care 2002.

12. Neumann J. O. et. al: The use of hyperventilation therapy aftertraumatic brain injury in Europe:an Analysis of the BrainIT Database. Intensive Care Med. 10.1007.

13. Roukoz B. Chamoun, Shankar P. et. al :Cerebral Metabolism in the Management of TBI Patients

14. Zauner A., Muizelaar J. P: Brain Metabolism and Cerebral B lood flow. J. Head Injury. Chapman and Hall. London 1997.

15. Guyton A.C : Texbook of Medical Physiology. 5ed. Phyladelfia. WB.Sounders, 1983. 69-71.
Rob Law, H.Bukwirwa: Physiology of Oxygen Deliver. Update in Anaesthesia, edition 10 (1999).

16. Robertson C,:Every Breath You Take: Hyperventilation And Intracranial Pressure. Cleveland Clinic Journal Of Medicine.vol 71 -Cleveland Supplement. 2004.

17. Len T. K., Neary JP, Asmundson GJ,et. al :Cerebrovascular Reactivity Impairment After Sport-Induced Concussion. Med. Sci. Sports Exerc. Vol. 43. No. 12. 2011. pp. 2241-2248.

18. Schubert A. Brain Protection in Clinical Neuroanesthesia, Boston. ButterworthHeinemann. 1997.

19. Hulst V RA, Hasan D, Lachmann B: Intracranial Pressure, Brain Pco2, Po2, And Ph During HypoAnd Hyperventilation At Constant Mean Airway Pressure In Pigs.Intensive Care Med. 2002 Jan;28(1):68-73. Epub 2001 Nov 23. Linkhttp://www.ncbi.nlm.nih.gov/pubmed/1181900 3.

20. Toda N, Ayaki K, okamura T. Cerebral Blood Flow Regulation by Nitrc Oxide: Recent Advances. J. Pharmacological Revews.vol 61. 2009.

21. Alex B. Valadka, BianT, Andrews. Neurotrauma. Thieme Medical Publisher, 2005.

22. Ausina A, et all. Intracranial Presur and neuromonitoring in patient severe head Injury: Can Hyperventilation cause Brain Edema.

23. Granacher, R. Traumatic Brain Injury Methods for clinical and forensic neuropsychiatricAsessment. CRC Press LLC.New York. 2003.

24. Reilly P. Bullock R. Pathophysiology and management of severe closed injury in: Head Injury. Chapman and Hall. London. 1997.

25. Simon M, Andrew B, Mark CB. Intensive Care, 2nd ed, Elsevier Churchill Livingstone, 2006

26. Lynelle N.B, Mechanical Ventilation and Intensive Respiratory Care, WB Saunders Company, 1995

27. Dahlan M.S,. Statistika Untuk Kedokteran Dan Kesehatan. Pt Arkans. 2004.

28. John w. Earl rrt, bs. Delivery Of High Fio2. The Science Journal Of The American Association For Respiratory Care. Open Forum Abstracts. 2003. Download dari:http://www.rcjournal.com/abstracts/2003/?id= OF-03-257. 